\title{
Time to consider neuroinflammation as a booster effect of cerebral venous sinus thrombosis in vaccine-induced immune thrombotic thrombocytopenia?
}

\author{
Benjamin Marchandot ${ }^{1}\left[\right.$ D Adrien Carmona $^{1} \cdot$ Olivier Morel $^{1,2}$
}

Accepted: 26 September 2021 / Published online: 9 November 2021

(c) The Author(s), under exclusive licence to Springer Science+Business Media, LLC, part of Springer Nature 2021

\begin{abstract}
Abbreviations
CVST Cerebral venous sinus thrombosis

VITT Vaccine-induced Immune thrombotic thrombocytopenia
\end{abstract}

\section{To the Editor,}

Rare cases of vaccine-induced immune thrombotic thrombocytopenia (VITT) and cerebral venous sinus thrombosis (CVST) have been reported after ChAdOx1 nCoV-19 (Oxford-AstraZeneca) and Ad26.COV2.S (Johnson\&Johnson/Janssen) vaccination. VITT is known to affect 1 per 100.000 vaccinated people irrespective of age and up to 1 in 50000 for people $<50$ years of age [1]. VITT is associated with the detection of anti-PF4 antibodies, unrelated to previous use of heparin therapy, that activate platelets via the platelet Fc $\gamma$ RIIA receptors, cause platelet activation, thrombosis, and thrombocytopenia. VITT has lately been acknowledged as a pancellular activation process with multiple converging prothrombotic pathways that include platelets and monocyte activation via Fc receptors, neutrophil activation (NETs) and endothelial stimulation [1][2]. Although VITT has rapidly benefited from expert guidance on both diagnosis and management, the pathogenic mechanism remains to be explored. Hypotheses in relation to the adenoviral vector vaccine platforms' induction of VITT include binding of adenovirus to coagulation factors triggering clot formation; vaccine induced secretion of spike

Olivier Morel

olivier.morel@chru-strasbourg.fr

1 Division of Cardiovascular Medicine, Nouvel Hôpital Civil, Strasbourg University Hospital, 1 place de l'Hôpital, 67000 Strasbourg, France

2 INSERM (French National Institute of Health and Medical Research), UMR 1260, Regenerative Nanomedicine, FMTS, 67000 Strasbourg, France protein activating endothelial cells through ACE2 and triggering vascular thromboinflammation; anti-vector $\mathrm{T}$ cell responses; binding of adenovirus capsid to PF4; impurities of human or non-structural viral proteins in vaccine preparation triggering anti-PF4 [3].

VITT shares high similarities with autoimmune heparininduced thrombocytopenia (aHIT) [4]. The overall incidence of CVST is 1.32 per 100000 person-years [5], about $1 \%$ of patients with HIT [6], and CVST secondary to aHIT only identified in 21 cases in the literature [7]. VITT is associated with an increased risk for CVST and splanchnic vein thrombosis as compared to other "common" locations of venous thrombotic events such as deep vein thrombosis and pulmonary embolism. CVST in VITT often involved many of the venous sinuses with thrombi extending into the venules [8]. Hence, it remains unclear why there is a peculiar preference for the cerebral sinus veins. While much attention has been paid on the potential mechanisms of VITT, no investigation has addressed so far, the reason why thrombosis in VITT has a specific tropism for venous sinuses [9][10].

Apart from thrombo-embolic events, severe adverse reactions following adenovirus vector COVID-19 vaccination include capillary leak syndrome (very rare) and three inflammatory adverse reactions: myocarditis (3.0 per million doses), pericarditis (1.7 per million doses) [11] and rare cases of Guillain-Barré Syndrome [12]. Inflammationrelated adverse reactions following adenovirus-vectored COVID-19 vaccines indicate a marked vaccine reactogenicity [13]. In line with this view, Menni et al. reported a higher incidence of systemic side-effects after a first dose of AstraZeneca $(n=116.473(33.7 \%))$ as compared to the Pfizer vaccine $(n=38.155(13.5 \%))$ among 627.383 UK patients [14]. Especially, a 3.6-fold increase in headaches was reported by the authors after a first dose of ChAdOx1 nCoV-19 (78.734 (22.8\%) vs $21.910(7.8 \%))$ as compared to BNT162b2. Upon vaccination, mediators of inflammation initially produced at a localized site may spread throughout the vasculature and boost a systemic inflammatory 
response. Inflammation is triggered at a localized site in the body with activation of immune cells, mast cells, monocytes and macrophages within minutes of injection. Release of inflammatory markers in the bloodstream (proinflammatory cytokines, chemokines, effectors of the complement cascade etc.) may promote an inflammatory response to the central nervous system [13] via receptors on the vagus nerve, at the blood-brain barrier and the circumventricular organs [15] [16]. This translates in elevated intracerebral levels of pyrogenic cytokines (e.g. interleukin-1, interleukin-6, tumour necrosis factor-alpha, prostaglandin-E2 etc.).

Salih et al. recently introduced the concept of a «preVITT syndrome» for those with severe headache, high d-dimer levels, positive anti-PF4 antibodies but no CVST or other thromboses [17]. Severe headache did not develop secondary to CVST but instead proceeded CVST. The authors suggested that headache was likely due to microthrombosis in smaller cortical veins. A post-mortem examination of VITT cases confirmed extensive vascular thrombotic occlusions occurring in the microcirculation of multiple organs and increased inflammatory infiltrates [18]. Immunohistochemical analyses showed high expression of adhesion molecules (VICAM1), complement components, CD66b +, CD163 + and CD61 + [18]. Both the innate immune system and complement pathway are thought to promote microvascular damage and thrombo-inflammation. These findings underscore that the VITT cascade is a highly dynamic system with cerebral microthrombosis supposed to occur first in patients with positive anti-PF4 antibodies causing headache. Then, high titers of anti-PF4 antibodies activate platelets and induce neutrophil activation and NETs formation, leading to thrombosis in larger sized vessels [19]. Anti-PF4 antibodies in VITT have been demonstrated to mimic the effect of heparin by binding to a similar site on PF4, allowing PF4 tetramers to cluster and form immune complexes, which in turn cause Fc $\gamma$ RIIa-dependent platelet activation [20]. A proinflammatory milieu is key in the pathogenesis of VITT together with a massive innate immune activation, extensive degranulation of neutrophils, tissue, and endothelial damage and NETosis [2][19].

Currently, the role of neuroinflammation defined as meningeal irritation/inflammation after COVID-19 adenoviral vector vaccination has not been addressed as a potential booster effect of cerebral thrombosis in VITT. Two distinct and potentially complementary pathways may trigger neuroinflammation after adenovirus vector COVID-19 vaccination and represent a major hub in the bidirectional interplay between inflammation and thrombosis in VITT and CVST.

First, systemic release of inflammatory mediators following vaccination can lead to increased levels of intracerebral mediators and products of inflammation. This can promote endothelial stimulation leading to the exposure of procoagulant phospholipid at the outer leaflet of the plasma membrane, tissue factor, vWF and P-selectin expression [21] [22] locally in the brain and contribute to a dysregulated and excessive activation of immunothrombosis resulting in thrombo-inflammation, causing tissue ischaemia by microvascular and macrovascular thrombosis.

Second, mimicking the neuroinvasivity of SARS-CoV-2 [23], vaccine induced secretion of spike proteins binding ACE2 on cerebral endothelial cells may initiate cerebral vascular inflammation and damage with consequent platelet activation, favoring cerebral thrombotic events.

VITT is a new syndrome and current gap in knowledge include why certain vascular beds are more susceptible to thrombosis. The frequent coexistence of splanchnic vein and CVST remains unclear sinus thrombosis. Given the close interplay between inflammation and thrombosis, further research specifically designed to assess the potential role for meningeal irritation and inflammation in triggering a vascular endothelial cells substrate suitable for CVST may be of interest. Targeting neuroinflammation to prevent thromboinflammation is an appealing concept not yet covered by current preventive and therapeutic measures in COVID-19 vaccination.

Author's contribution The manuscript has been read and approved for submission by all authors. All the authors take responsibility for all aspects of the reliability and freedom from bias of the data presented and their discussed interpretation. All the authors take responsibility for all aspects of the reliability and freedom from bias of the data presented and their discussed interpretation.

Funding O.M received institutional research grants from Fondation Coeur et Vaisseaux, AstraZeneca and Boehringher Ingelheim.

\section{Declarations}

Conflict of interest The authors declare that there is no conflict of interest regarding the publication of this article.

\section{References}

1. Marchandot B, Curtiaud A, Trimaille A, Sattler L, Grunebaum L, Morel O (2021) Vaccine-induced immune thrombotic thrombocytopenia: current evidence, potential mechanisms, clinical implications, and future directions. Eur Heart J Open. https://doi.org/10. 1093/ehjopen/oeab014

2. Holm S, Kared H, Michelsen AE, Kong XY, Dahl TB, Schultz NH, Nyman TA, Fladeby C, Seljeflot I, Ueland T, Stensland M, Mjaaland S, Goll GL, Nissen-Meyer LS, Aukrust P, Skagen K, Gregersen I, Skjelland M, Holme PA, Munthe LA, Halvorsen B (2021) Immune complexes, innate immunity, and NETosis in ChAdOx1 vaccine-induced thrombocytopenia. Eur Heart J. https://doi.org/10.1093/eurheartj/ehab506

3. Othman M, Baker AT, Gupalo E, Elsebaie A, Bliss CM, Rondina MT, Lillicrap D, Parker AL (2021) To clot or not to clot? Ad is the question-insights on mechanisms related to vaccine induced 
thrombotic thrombocytopenia. J Thromb Haemost. https://doi.org/ $10.1111 /$ jth. 15485

4. Warkentin TE, Greinacher A (2021) Spontaneous HIT syndrome: Knee replacement, infection, and parallels with vaccine-induced immune thrombotic thrombocytopenia. Thromb Res 204:40-51. https://doi.org/10.1016/j.thromres.2021.05.018

5. Coutinho JM, Zuurbier SM, Aramideh M, Stam J (2012) The incidence of cerebral venous thrombosis: a cross-sectional study. Stroke 43(12):3375-3377. https://doi.org/10.1161/STROKEAHA. 112.671453 (Epub 2012 Sep 20 PMID: 22996960)

6. Warkentin TE (2013) Clinical picture of heparin-induced thrombocytopenia. In: Warkentin TE, Greinacher A (eds) Heparininduced Thrombocytopenia, 5th edn. CRC Press, Boca Raton, FL, pp 24-76

7. Bauman MMJ, Naylor RM, Wijdicks EF (2021) HIT in the head: a systematic review of cerebral venous sinus thrombosis in classical and autoimmune heparin-induced thrombocytopenia. J Thromb Thrombolysis. https://doi.org/10.1007/s11239-021-02484-6

8. Pavord S, Scully M, Hunt BJ, Lester W, Bagot C, Craven B, Rampotas A, Ambler G, Makris M (2021) Clinical features of vaccine-induced immune thrombocytopenia and thrombosis. $\mathrm{N}$ Engl J Med. https://doi.org/10.1056/NEJMoa2109908

9. Rizk JG, Gupta A, Sardar P, Henry BM, Lewin JC, Lippi G, Lavie CJ (2021) Clinical characteristics and pharmacological management of covid-19 vaccine-induced immune thrombotic thrombocytopenia with cerebral venous sinus thrombosis: a review. JAMA Cardiol. https://doi.org/10.1001/jamacardio.2021.3444

10. Marchandot B, Carmona A, Trimaille A, Curtiaud A, Morel O (2021) Procoagulant microparticles: a possible link between vaccine-induced immune thrombocytopenia (VITT) and cerebral sinus venous thrombosis. J Thromb Thrombolysis. https://doi.org/ 10.1007/s11239-021-02505-4

11. Research and analysis Coronavirus vaccine - weekly summary of Yellow Card reporting Updated 6 August 2021 https://www.gov. uk/government/publications/coronavirus-covid-19-vaccine-adver se-reactions/coronavirus-vaccine-summary-of-yellow-card-repor ting. Last Accessed August 10, 2021

12. Dyer O (2021) 2021 Covid-19: Regulators warn that rare GuillainBarré cases may link to J\&J and AstraZeneca vaccines. BMJ. 374:n1786. https://doi.org/10.1136/bmj.n1786

13. Hervé C, Laupèze B, Del Giudice G, Didierlaurent AM, Tavares Da Silva F (2019) The how's and what's of vaccine reactogenicity. NPJ Vaccines. https://doi.org/10.1038/s41541-019-0132-6

14. Menni C, Klaser K, May A, Polidori L, Capdevila J, Louca P, Sudre CH, Nguyen LH, Drew DA, Merino J, Hu C, Selvachandran S, Antonelli M, Murray B, Canas LS, Molteni E, Graham MS, Modat M, Joshi AD, Mangino M, Hammers A, Goodman AL, Chan AT, Wolf J, Steves CJ, Valdes AM, Ourselin S, Spector TD (2021) Vaccine side-effects and SARS-CoV-2 infection after vaccination in users of the COVID Symptom Study app in the UK: a prospective observational study. Lancet Infect Dis. https://doi. org/10.1016/S1473-3099(21)00224-3

15. Roth J, Harré EM, Rummel C, Gerstberger R, Hübschle T (2004) Signaling the brain in systemic inflammation: role of sensory circumventricular organs. Front Biosci. 9:290-300

16. Rivest $S$ (2003) Molecular insights on the cerebral innate immune system. Brain Behav Immun 17(1):13-19. https://doi.org/10.1016/ s0889-1591(02)00055-7

17. Salih F, Schönborn L, Kohler S, Franke C, Möckel M, Dörner T, Bauknecht HC, Pille C, Graw JA, Alonso A, Pelz J, Schneider H, Bayas A, Christ M, Kuramatsu JB, Thiele T, Greinacher A, Endres M (2021) Vaccine-Induced Thrombocytopenia with Severe Headache. N Engl J Med. https://doi.org/10.1056/NEJMc21129 74

18. Pomara C, Sessa F, Ciaccio M, Dieli F, Esposito M, Garozzo SF, Giarratano A, Prati D, Rappa F, Salerno M, Tripodo C, Zamboni P, Mannucci PM (2021) Post-mortem findings in vaccine-induced thrombotic thombocytopenia. Haematologica 106(8):2291-2293. https://doi.org/10.3324/haematol.2021.279075

19. Greinacher A, Selleng K, Wesche J, Handtke S, Palankar R, Aurich K, Lalk, Karen Methling M, Vo"lker U, Hentschker C, Michalik S, Steil L, Scho"nborn L, Beer M, Franzke K, Rangaswamy C, Mailer RK, Thiele T, Kochanek S, Krutzke L, Siegerist F, Endlich N, Warkentin TE, Renné T. 2021 Towards understanding ChAdOx 1 nCov- 19 vaccine-induced immune thrombotic thrombocytopenia (VITT). Doi:https://doi.org/10.21203/rs.3.rs$440461 / \mathrm{v} 1$

20. Huynh A, Kelton JG, Arnold DM, Daka M, Nazy I (2021) Antibody epitopes in vaccine-induced immune thrombotic thrombocytopaenia. Nature 596(7873):565-569. https://doi.org/10.1038/ s41586-021-03744-4 (Epub 2021 Jul 7)

21. Aksu K, Donmez A, Keser G (2012) Inflammation-induced thrombosis: mechanisms, disease associations and management. Curr Pharm Des 18(11):1478-1493. https://doi.org/10.2174/13816 1212799504731

22. Wagner DD (2005) New links between inflammation and thrombosis. Arterioscler Thromb Vasc Biol 25(7):1321-1324. https:// doi.org/10.1161/01.ATV.0000166521.90532.44

23. Pezzini A, Padovani A (2020) Lifting the mask on neurological manifestations of COVID-19. Nat Rev Neurol 16(11):636-644. https://doi.org/10.1038/s41582-020-0398-3 (Epub 2020 Aug 24)

Publisher's Note Springer Nature remains neutral with regard to jurisdictional claims in published maps and institutional affiliations. 